\title{
O GRUPO CAIUÁ (Ks): REVISÃO ESTRATIGRÁFICA E CONTEXTO DEPOSICIONAL*
}

\author{
LUIZ ALBERTO FERNANDES** \& ARMANDO MÁRCIO COIMBRA***
}

\begin{abstract}
THE CAIUÁ GROUP (LATE CRETACEOUS): STRATIGRAPHIC REVIEW AND DEPOSITIONAL SETTING. A stratigraphic review of the Late Cretaceous sediments deposited on the Paraná Flood volcanics is presented in this paper. The review is mainly based on studies developed by Fernandes (1992) in the northwest of the Paraná and on the westernmost part of São Paulo states. Stratigraphic and sedimentologic characteristics of the units of the Caiuá Group, as well as the depositional environments and its paleogeographic distribution in the southwest part of the Bauru Basin (a Late Cretaceous depression developed in the south-central part of the South American Platform by thermo-mechanical subsidence) are discussed. This inland basin preserved a single sequence, wich is mainly of quartz sandstones and sandy mudstones (red beds) - with locally associated volcanic rocks - encompassing several stratigraphic units known as Bauru Group. This suprabasaltic cover is composed of two synchronous groups: Caiuá (with the Goio Erê, Rio Paraná and Santo Anastácio formations), and Bauru (with the Marflia, Adamantina, Uberaba formations, and the Taiúva Analcimites).The Santo Anastácio Formation (SAP) is composed of very fine to fine quartz sandstones, that sometimes exhibits incipient planar parallel or low inclinated cross bedding. The Rio Paraná (RPF) and Goio Erê (GEF) formations are composed of fine from very fine quartz sandstones. They are differentiated by the geometry of the lithofacies, degree of maturity (textural and mineralogic), and geographic position in the basin. The RPF is characterized by large cross bedding sets and high textural and mineralogical maturity, whereas the GEF shows typical massive or small scale cross-bedding, and is composed of sandstones of low degree of maturity, with frequent carbonate cement and concretions. The sequence deposited under semi-arid paleoclimate in an asymmetric endorheic basin, with more desertic conditions towards its interior. The Caiuá Group comprises aeolian deposits of sand sea in an interior paleodesert of the basin. The Bauru Group comprises alluvial deposits, that includes marginal alluvial fans to distal facies accumulated on broad plains of braided streams with ephemeral alkaline water lakes.
\end{abstract}

Keywords: Caiuá, Santo Anastácio, Bauru, Cretaceous, Paraná Basin, Bauru Basin, stratigraphy, depositional environments, paleogeography.

RESUMO O artigo apresenta uma revisão estratigráfica da cobertura neocretácea suprabasáltica. Baseiase em estudos de caráter sobretudo sedimentológico e paleogeográfico desenvolvidos no noroeste do Paraná e no extremo oeste do Estado de São Paulo (Fernandes 1992), onde tal cobertura foi tratada como uma seqüência sedimentar única acumulada na Bacia Bauru, na porção centro-sul da Plataforma Sul-Americana. A seqüência é constituída por rochas siliciclásticas de origem continental e rochas vulcânicas localmente associadas, compreendendo diversas unidades litoestratigráficas anteriormente reunidas no Grupo Bauru. Na concepção ora apresentada ela é composta por dois grupos cronocorrelatos: Caiuá (formacões Santo Anastácio, Rio Paraná e Goio Erê) e Bauru (formaçôes Adamantina, Marília e Uberaba). Neste último também são incluídas as rochas extrusivas intercaladas na Formação Adamantina (em São Paulo), sob a designação de Analcimitos Taiúva. A Formação Santo Anastácio é constituída por arenitos quartzosos muito finos a finos, maciços, às vezes com estratificação plano-paralela ou cruzada de baixa inclinação mal definidas. As formações Rio Paraná e Goio Erê são compostas por arenitos quartzosos finos a muito finos. Diferenciam-se pelo arranjo geométrico dos litossomas, maturidade (textural e mineralógica), e apresentam disposição geográfica distinta na bacia. A primeira caracterizase por unidades de estratos cruzados de grande porte e elevado grau de maturidade textural e mineralógica. A segunda exibe arranjo típico em camadas de esspessura média decimétrica, internamente maciças ou com estratificação cruzada de médio a pequeno porte. E formada por arenitos de menor maturidade que a Formação Rio Paraná, com freqüente cimentação e concrecões de carbonato. A seqüência neocretácea é constituída por arenitos e lamitos arenosos, quartzosos, que formam depósitos de origem continental acumulados em clima quente, semiárido a árido. As unidades do Grupo Caiuá correspondem a depósitos eólicos de sand sea instalado na parte interna da Bacia Bauru. O Grupo Bauru reúne unidades acumuladas ao redor do paleodeserto interior, entre a zona desértica e os limites da bacia. Este grupo corresponde aos depósitos de sistemas aluviais, e abrange desde as partes distais de extensas planícies fluviais com lagoas alcalinas efêmeras, até os leques de borda.

Palavras-chave: Caiuá, Santo Anastácio, Bauru, Cretáceo, Bacia do Paraná, Bacia Bauru, estratigrafia, ambientes deposicionais, paleogeografia.

INTRODUÇ̃̃O As unidades da seqüência cretácea suprabasáltica foram consideradas como pertencentes à Bacia do Paraná, embora fossem tratadas em diversas oportunidades como acumuladas em sítio deposicional de características singulares (e,g. Almeida 1956, Arid 1970, Coimbra 1976, Suguio 1981, Saad et al 1988, Fúlfaro \& Barcelos 1992).

No início do Cretáceo Inferior a crosta terrestre foi submetida a colossal fendilhamento, quando ocorreram a ruptura do megacontinente Gondwana e a abertura do Oceano
Atlântico Sul. A tais transformações associou-se o "magmatismo Serra Geral", evento de proporções sem similares na história do Planeta. Estes processos promoveram mudanças significativas na evolução da Plataforma SulAmericana, criando-se novas condições para a sedimentação intracratônica. Na parte centro-meridional desta plataforma acumulou-se a seqüência suprabasáltica, numa depressão de evolução geológica e de depocentro distintos dos da Bacia do Paraná, na denominada Bacia Bauru (Fernandes 1992).

\footnotetext{
* Desenvolvido com suporte financeiro da FAPESP (Projeto Geologia 87/2722-7)

** Instituto de Pesquisas Tecnológicas do Estado de São Paulo (IPT); Doutorando do IGc/USP. Caixa Postal 7141. CEP 01064-970 São Paulo, SP, Brasil. Fax: 5511 869.6383. E-mail: LFERNAND@USP.BR
}

*** Instituto de Geociências - Universidade de São Paulo; Bolsista do CNPq. Caixa Postal 11.348, CEP 05422-970, São Paulo, SP, Brasil. Fax 55 11 818.4129 


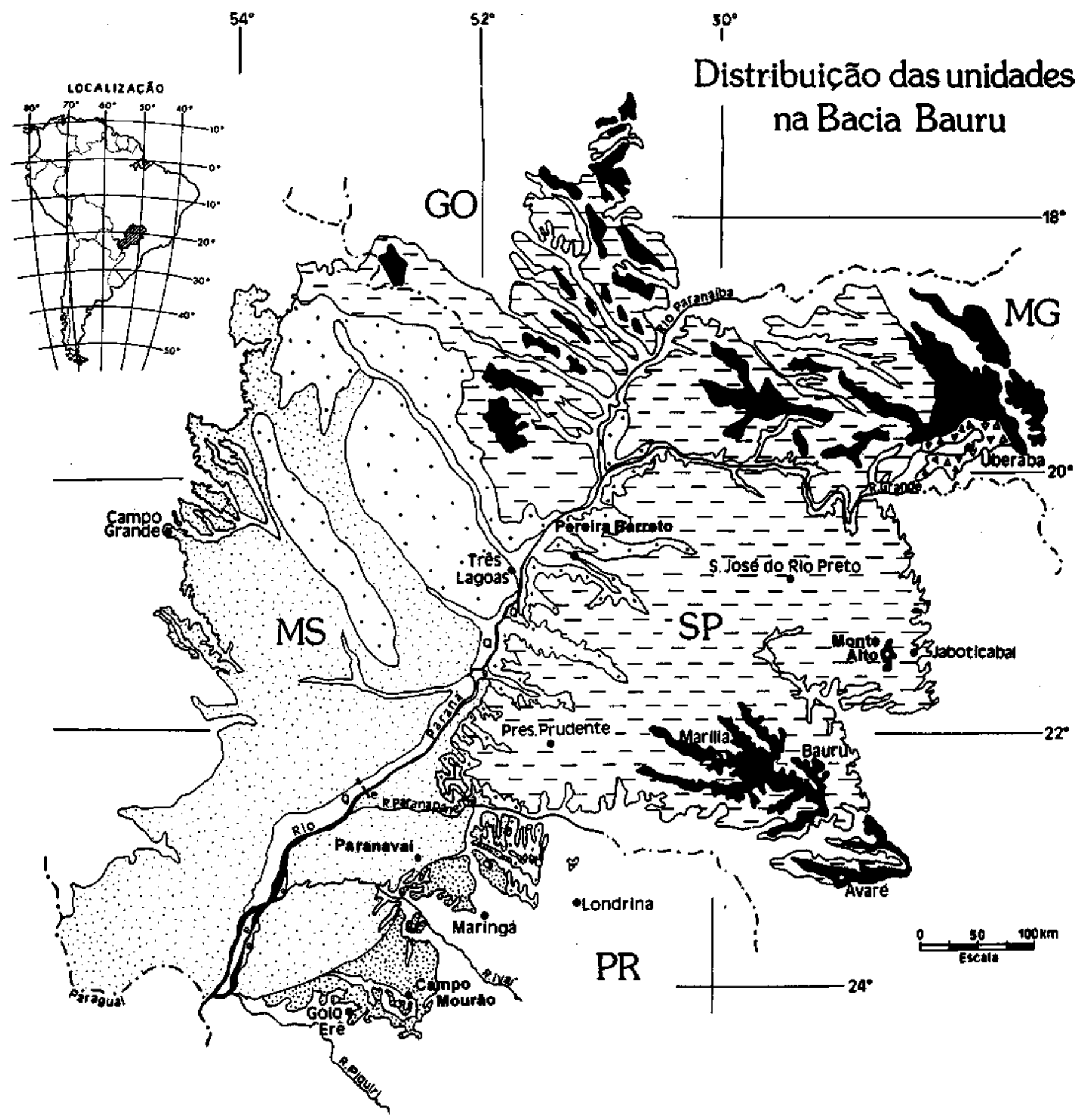

LEGENDA

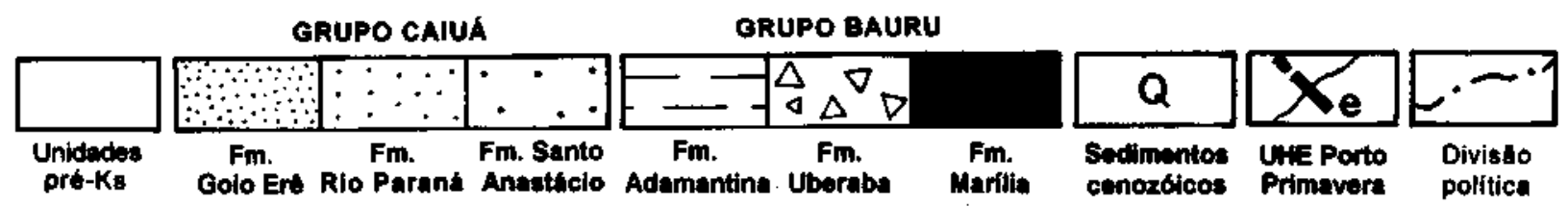

Figura 1 - Mapa de distribuição da cobertura neocretácea suprabasáltica no sul do Brasil

Figure 1 - Distribution of the Late Cretaceous units in Southern Brazil 
A cobertura suprabasáltica neocretácea estende-se atualmente pelo Planalto Ocidental de São Paulo, noroeste do Paraná, parte oriental do Mato Grosso do Sul, parte do Triângulo Mineiro (MG) e sul de Goiás (Fig. 1). Constitui-se de rochas sedimentares de origem continental, acumuladas durante o Cretáceo Superior, com rochas vulcânicas localmente intercaladas.

$\mathrm{O}$ estudo da cobertura sedimentar suprabasáltica teve início nos primórdios do século, com a notificação da descoberta de nova unidade sedimentar sobre as rochas eruptivas (Gonzaga de Campos 1905), nas imediações de Bauru, em São Paulo. Aos estudos pioneiros seguiram-se diversos ensaios e discussões de caracterização litológica, conteúdo paleontológico, cronologia e estratigrafia das então designadas como formações Bauru e Caiuá, cujas primeiras representações em mapas regionais devem-se a Florence \& Pacheco (1929) e Maack (1941).

A unidade Santo Anastácio foi definida por Landim \& Soares (1976) como fácies independente, de transição entre as unidades Bauru e Caiuá ou como membro inferior do Grupo Bauru. Até então os arenitos Santo Anastácio haviam sido cartografados indistintamente com os arenitos Caiuá. Stein et ai. (1979) promoveram a unidade Santo Anastácio à formação, situando-a estratigraficamente entre as unidades Bauru e Caiuá.

Soares et al. $(1979,1980)$ propuseram uma organização estratigráfica para o Cretáceo no Estado de São Paulo, em que a unidade Bauru - apresentada como grupo - incorporava os arenitos Caiuá e Santo Anastácio. Segundo estes autores, o Grupo Bauru seria então constituído pelas formações Caiuá, Santo Anastácio, Adamantina e Marília. Largamente aceita nos anos 80 , esta proposta foi parcialmente modificada em estudos posteriores, dentre os quais destacam-se os de Almeida et al (1980), Suguio (1981), Brandt Neto 1984, Barcelos 1984, Barcelos \& Suguio (1987). Por outro lado, ainda que por razões diversas, outros autores retomaram idéias de desvinculação das formações Caiuá e Santo Anastácio do Grupo Bauru (Mezzalira 1982, Bigarella \& Mazuchowski 1985, Fúlfaro \& Barcelos 1993).

REVISÃO ESTRATIGRÁFICA DA UNIDADE CAIUÁ Historicamente, a Formação Caiuá (incorporando os arenitos Santo Anastácio) foi tratada como unidade litológica de identidade própria. Esta concepção manteve-se desde sua definição formal (Washburne 1930) e das primeiras representações em mapa (Florence \& Pacheco 1929, Maack 1941), até o penúltimo mapa geológico do Estado de São Paulo (IGG 1974).

Antes do estabelecimento da clássica organização estratigráfica de Soares et al (1979 e 1980), as unidades Caiuá e Bauru coexistiram independentes, em geral como formações. Isto se deve principalmente a duas razões:

1) litológica: as duas unidades possuem características litológicas distintas, relatadas desde as primeiras descrições dos arenitos Caiuá (Baker 1923, Washburne 1930, Maack 1941) e da unidade Bauru (Gonzaga de Campos 1905 , Pacheco 1913, Washburne 1930 Setzer 1943, Almeida \& Barbosa 1953, entre outros). É oportuno ressaltar que os arenitos nomeados de Bauru por Gonzaga de Campos (1905) foram descritos em áreas restritas às de exposição das atuais formações Adamantina e Marília;

2) os arenitos Caiuá afloram principalmente no Paraná, onde são praticamente ausentes as outras unidades. Já em São Paulo, onde surgiram as principais propostas de estratigrafia para as unidades neocretáceas, ocorre o inverso. Ali, as formações Adamantina e Marília dominam sobre as outras unidades quanto à área de exposição. Tais circunstâncias devem ter influenciado na criação dos modelos estratigráficos, os quais refletem, em maior ou menor grau, experiências regionais.
Com base em características litológicas, relações estratigráfícas e distribuição geográfica de associações faciológicas identificadas no noroeste do Paraná e extremo oeste de São Paulo, Fernandes (1992) dividiu a unidade Caiuá nas formações Goio Erê e Rio Paraná, o que levou a sua conseqüente elevação à categoria de grupo.

No presente artigo propõe-se a definiç̧ão formal do Grupo Caiuá como a reunião das formações Goio Erê, Rio Paraná e Santo Anastácio. Em decorrência, o Grupo Bauru passa a compor-se pelas formações Adamantina, Marília, Uberaba, e as rochas extrusivas (intercaladas na primeira) ora designadas como Analcimitos Taiúva (Fig. 2).

\section{RELAÇÕES ENTRE AS UNIDADES}

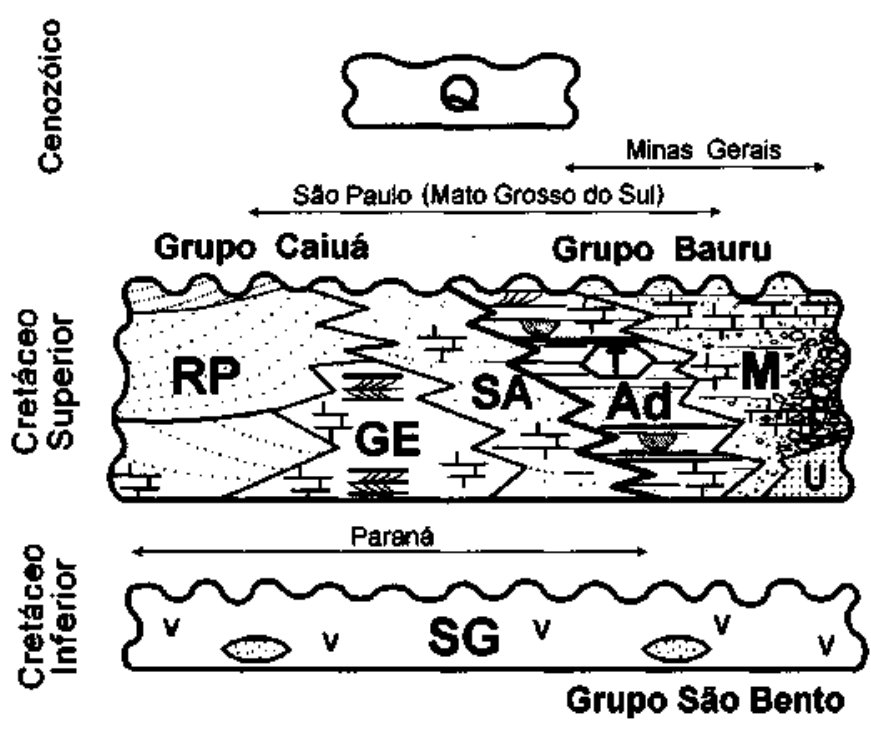

Figura 2 - Relações entre as unidades litoeslratigráficas da seqüencia neocretácea na Bacia Bauru. Convenções: SG. Fm. Serra Geral; RP. Fm. Rio Paraná, GE. Fm. Goio Erê, SA. Fm. Santo Anastácio, Ad. Fm. Adamantina, U. Fm. Uberaba, M. Fm. Marília, T. Analcimitos Taiúva; Q. sedimentos aluviais quaternários

Figure 2 - Stratijgraphic relationships in the Late Cretaceous suprabasaltic cover. Key: SG. Serra Geral Fm.; RP. Rio Paraná Fm., GE. Goio Erê Fm., SÁ. Santo Anastácio Fm., Ad. Adamantina Fm., U. Uberaba Fm., M. Marília Fm., T. Taiúva Analcimites; Q. Quaternary alluvial sediments

O Grupo Caiuá reúne três unidades de arenitos acumuladas em ambiente desértico, geneticamente relacionadas, correspondentes a sub-ambientes distintos: zona central de sand sea, (Fm. Formação Rio Paraná), zona de depósitos eólicos periféricos (Fm. Goio Erê) e planícies de lençóis de areia (Fm. Santo Anastácio). O Grupo Bauru, cronocorrelato ao Caiuá, compreende associações facilógicas de ambiente aluvial: fluvial (formações Uberaba e Adamantina), leques marginais (Fm. Marília). Os Analcimitos Taiúva (Fernandes 1992) foram incluídos neste grupo por se tratarem de rochas extrusivas intercaladas na Fm. Adamantina, descritas apenas no Estado de São Paulo (Coimbra et al. 1981, Coutinho et al. 1982). De certo modo, a reunião das três unidades de origem eólica no Grupo Caiuá retoma a concepção estratigráfica dos estudos pioneiros dos arenitos designados como Caiuá (e.g. Florence \& Pacheco 1929, Washburne 1930) ou como São Bento Superior (e.g. Maack 1941, Bigarella 1949), onde as características litológicas e texturais foram critérios determinantes. 
CARACTERIZAÇÃO DAS UNIDADES DO GRUPO CAIUÁ No Brasil, o grupo ocorre nos estados do Paraná, São Paulo e Mato Grosso do Sul. No rumo sudoeste, ultrapassa a fronteira com o Paraguai, aflorando na região nordeste daquele país. Assenta-se em discordância sobre unidades do Grupo São Bento e apresenta contato transicional com a Formação Adamantina (Grupo Bauru).

$\mathrm{Na}$ concepção ora proposta, o Grupo Caiuá compõe-se por três formações: Goio Erê, Rio Paraná e Santo Anastácio. A Formação Goio Erê é caracterizada como arenitos dispostos em estratos tabulares maciços e com estratificação cruzada de médio/pequeno porte, alternados. Nesta unidade é freqüente a presença de cimento e concreções carbonáticas. A Formação Rio Paraná corresponde a arenitos bem selecionados, com estratificação cruzada de médio a grande porte característica. A Formação Santo Anastácio é constituída por arenitos, em geral maciços. As três unidades apresentam cores marron avermelhado a arroxeado, mais pálido para a última, características de red beds.

Formação Rio Paraná ÁREA DE OCORRÊNCIA E ESPESSURA Na parte sudoeste da sua área de ocorrência (Fig. 1) a Formação Rio Paraná apresenta espessuras máximas da ordem de 250 metros (Fig. 3). No Mato Grosso do Sul verificam-se valores em torno de 150 metros (Sousa Júnior 1984). Em superfície ocorrem, excepcionalmente, exposições contínuas com desníveis da ordem de 200 metros, como nos morros dos Três Irmãos (Terra Rica, noroeste do PR) e do Diabo (Teodoro Sampaio, oeste de SP), mantidas devido à silicificação localizada dos arenitos (Fernandes et al. 1993a). As maiores espessuras em perfurações são: 277 metros em Altônia e 205 metros em Terra Rica, ambas no Paraná.

LITOLOGIA E ESTRUTURAS A Formação Rio Paraná constitui-se de arenitos marrom-avermelhado a arroxeado, finos a médios, quartzosos, secundariamente subarcoseanos. Apresentam fração muito fina subordinada e, mais raramente, estratos de areia média a grossa. Mineralogicamente são

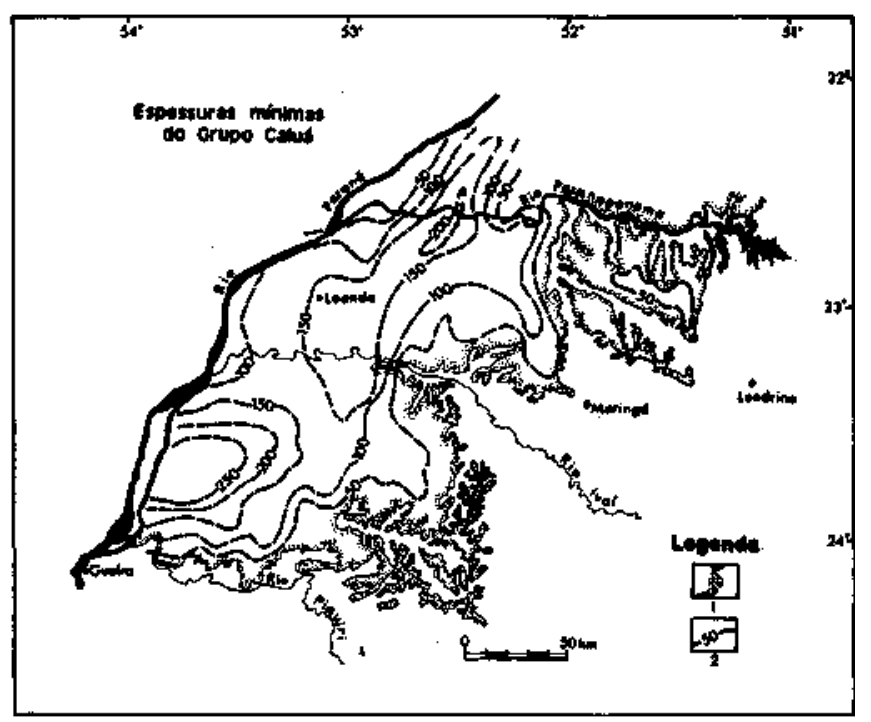

Figura 3-Mapa de espessuras mínimas do Grupo Caiuú no noroeste do Paraná e Pontal do Paranapanema (SP). Modificada de Fernandes (1992). Convenções: 1. limite da cobertura neocretâcea, 2. isópaca (em metros) Figure 3 - Map of minimum thickness of the Caiuá Group in northwest Paraná State and Pontal do Paranapanema regions (São Paulo State). Modified from Fernandes (1992). Key: 1. Late Cretaceous cover boundary, 2. isopach (in meters) supermaturos e possuem boa maturidade textural (Foto 1).

A Formação Rio Paraná exibe notável estratificação cruzada tabular de médio a grande porte (com seis de até 10 metros de altura), tangencial na base, em corpos de geometria cuneiforme limitados por superfícies de truncamento. A rocha apresenta conspícua laminação ou estratificação formada pela alternância de bandas de espessura centimétrica a milimétrica, de boa seleção interna (fotos $\mathrm{B}$ e $\mathrm{C}$ da Prancha 2) geradas por queda de grãos (grain fall) e por fluxo de grãos (grain flow). Este último processo ocorre com maior freqüência nas frentes de dunas (foresets), principalmente nas suas partes inferiores.

Em geral, os arenitos desta unidade são bem selecionados por lâmina ou estrato, com grãos bem arredondados nas frações mais grossas (Foto 2). A maioria dos grãos exibe superfície fosca, encoberta por película ferruginosa. Em 86 amostras analisadas encontrou-se quantidades de silte+argila entre 3 e $38 \%$ (média de $17, \%$ ), com 3 a 19\% (média de $10 \%$ ) de fração argila. Há que se considerar que parte do material argiloso, quantificado por análises granulométricas, provem de neoformação durante a diagênese e posterior alteração intempérica. Estes valores não correspondem, portanto, à quantidade original de material pelítico depositado como matriz, sobretudo o argiloso. De modo geral, o tom cinza-arroxeado dos arenitos está associado a revestimento de poros por argila autigênica (esmectita), que tende a ser substituída por caulinita por intemperismo (Fernandes et al, 1994).

Eventualmente observam-se estruturas sedimentares geradas em deslizamentos por gravidade, como lentes de fluxo de grãos, estratificação contorcida ou tabletes de arenito estratificado rotacionados (brechas de colapso), associadas à facies de foresets de dunas. $\mathrm{Na}$ zona central da área dê ocorrência da unidade são raras as feições de ressecação, como gretas e plaquetas de argila centimétricas (curled mudflakes). Na Figura 4 apresenta-se as principais feições e estruturas sedimentares características da unidade.

$\mathrm{Na}$ base da Formação Rio Paraná pode ser encontrada uma brecha (provável paleossolo) de espessura em torno de um metro - como no Pontal do Paranapanema - sustentada por matriz areno-argilosa com nódulos de esmectita e calcário. $\mathrm{O}$ arcabouço é composto por fragmentos

\section{ESTRUTURAS E FEIÇÓES CARACTERISTICAS}

Fm. Rio Paraná

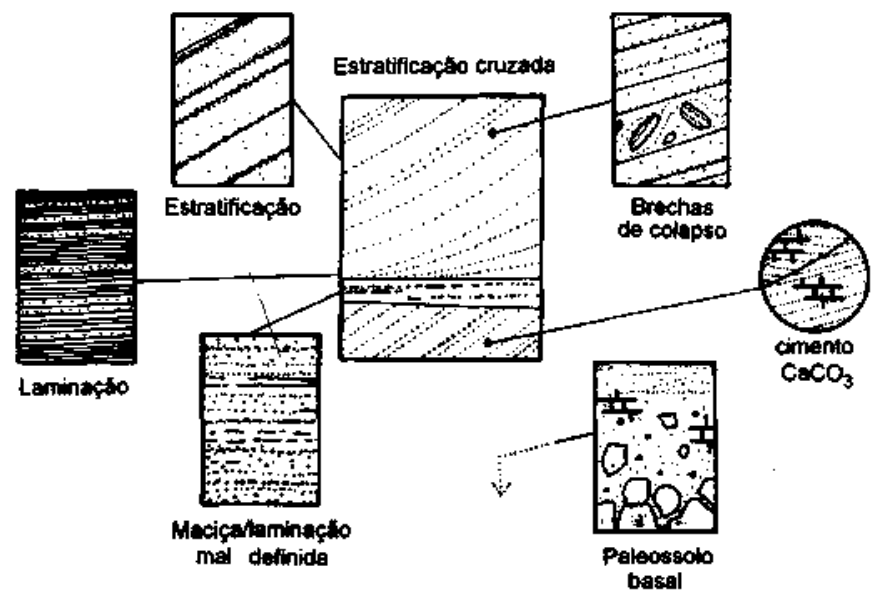

Figura 4 - Feições e estruturas sedimentares características da Formação Rio Paraná

Figure 4 - Features and sedimentary structures characteristics of the Rio Paraná Formation 

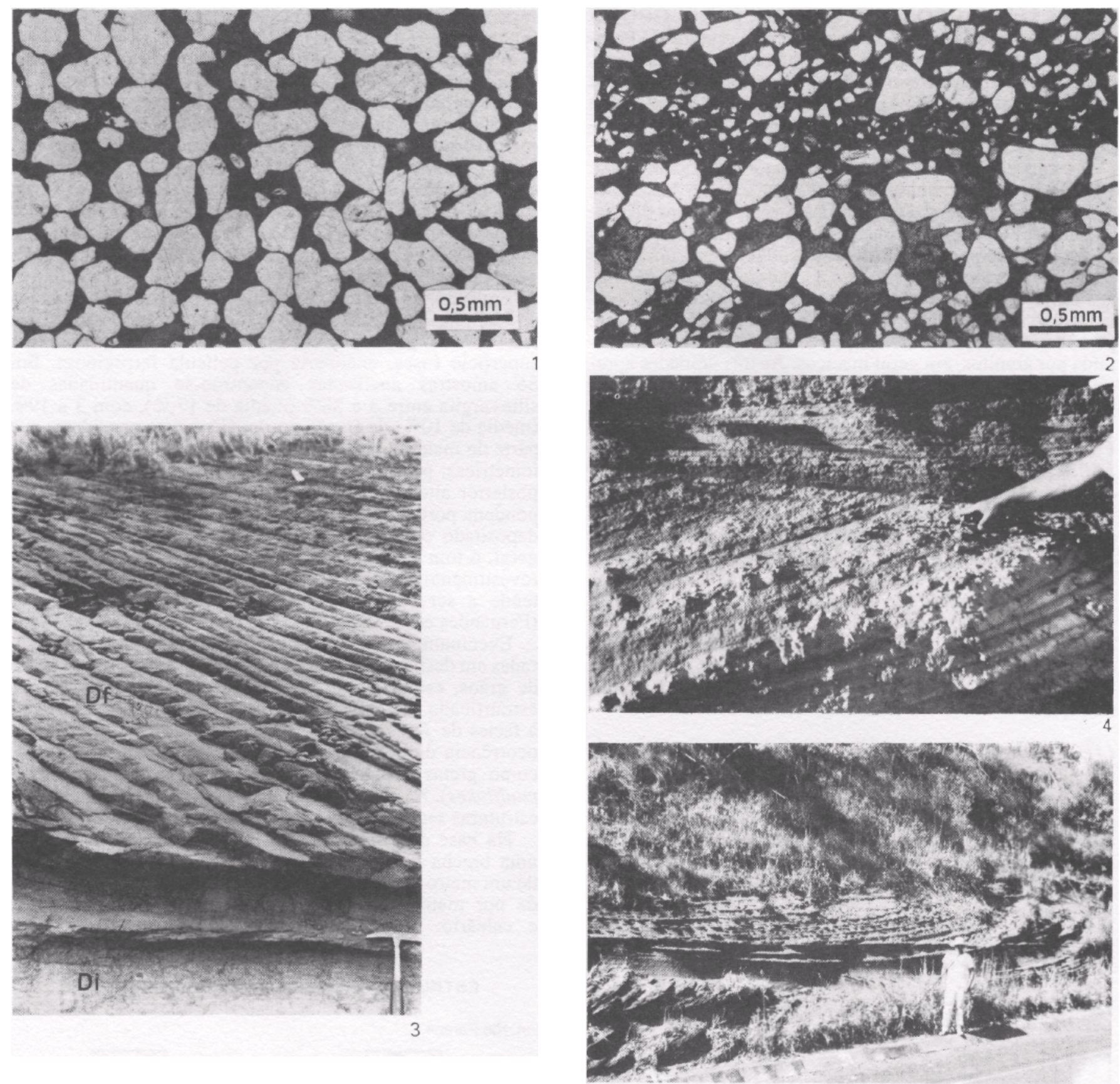

Prancha 1-1. Boa maturidade textural e mineralógica, características dos arenitos eólicos da Formação Rio Paraná. Fotomicrografia com polarizadores descruzados, de seção delgada de amostra de sub superficie. Área da UHE Porto Primavera (SP). 2. Laminação (bimodalidade) característica dos arenitos quartzosos eólicos da Formação Rio Paraná, e bom arredondamento dos grãos maiores. Fotomicrografia obtida com polarizadores descruzados, amostra de superficie da região da UHE Porto Primavera (SP). 3. Afloramento da Formação Rio Paraná na parede da eclusa da UHE Porto Primavera, exibindo estratificação eólica. Df: litofácies de foresets de duna) e Di: litofácies de interdunas. 4. Concreções carbonáticas (calcretes) em arenito com e stratificação cruzada da Formação Goio Erê. Corte da rodovia Campo MourãoGoio Erê (BR 272), $\mathrm{km}$ 46. 5. Arenitos com estratificação cruzada acanalada (foresets de dunas) sob camadas suhorizontais pobremente estratificadas a maciças (interdunas). Notar as crostas carbonáticas, comuns nesta unidade, que às vezes seccionam a e strati fie ação acanalada, em posição paralela aos estratos maciços. Formação Goio Erê, corte da rodovia Campo Mourão a Goio Erê (BR 272), situado a cerca de $9 \mathrm{~km}$ a leste desta localidade

Plate 1-1. Textural and mineralogic maturity of the Rio Paraná aeolian sandstones. Photomicrography of quartz sandstone thin section uncrossed nicols. Subsurface sample from the base of Rio Paraná Formation (Porto Primavera Hidroelectric Plant, São Paulo State). 2. Characteristic laminae (bimodality) of Rio Paraná quartz aeolian sandstones showing well rounded larger grains. Photomicrography outcrop uncrossed nicols. Surface sample of the Porto Primavera Hidroelectric Plant region (São Paulo State). 3. Rio Paraná Formation outcrop at the wall of the Porto Primavera Hidroelectric Plant canal, showing eolic stratification. Df: dune foresets lithofacies and Di: interdune lithofacies. 4. Carbonate concretions (calcretes) developed in cross-bedding sandstones of Goio Erê Formation. Campo Mourão to Goio Erê rnad cut (BR 272) at km 46.5. Trough cross-bedding sandstones (dune foresets) underlying poorly stratified to subhorizontal beds (interdunes). Notice the carbonate crusts, common in that unit, which sometimes cross the trough stratification in the massive beds. Goio Erê Formation, Campo Mourão-Goio Erê road cut (BR 272), 9 km to from this locality 
centimétricos angulosos, de basalto. Sobre a brecha é comum ocorrer um arenito silto-argiloso maciço, texturalmente imaturo (Foto A da Prancha 2). Tanto a brecha como o arenito estão freqüentemente cimentados por carbonato (provável calcrete), feição comum na parte basal da unidade (Fig. 5).

Nos cortes da eclusa da usina hidrelétrica Porto Primavera observa-se, ainda, dobras convolutas métricas entre porções não deformadas. Estas zonas perturbadas tiveram origem atribuída a atividades sísmicas ocorridas durante a sedimentação (Coimbra et al 1992).

SEÇÃO-TIPO Os cortes da eclusa da usina hidrelétrica Porto Primavera (Pontal do Paranapanema, SP) são aqui designados como holoestratótipo da Formação Rio Paraná (Fig. 6). Outra magnífica exposição da unidade situa-se no km 501 da rodovia BR 376, próximo a Paranavaí (PR). Ali se observam grandes feições acanaladas - seções transversais à construções barcanóides - devido à direção do corte, aproximadamente perpendicular ao rumo dominante do paleovento. Este local é indicado como seção complementar da Formação Rio Paraná, ou seja, seu paraestratótipo. Paredões de cerca de 15 metros de altura, da margem esquerda do Rio Paraná, constituem também boas exposições da unidade. Destacam-se aqueles próximos das localidades de Porto São José e Porto Rico, no Paraná, e de Presidente Epitácio, em São Paulo, indicados como hipoestratótipos.

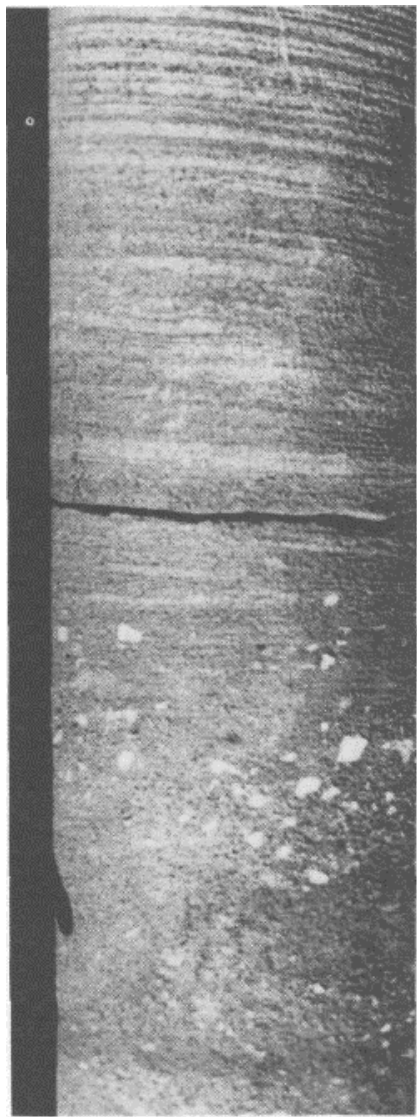

A

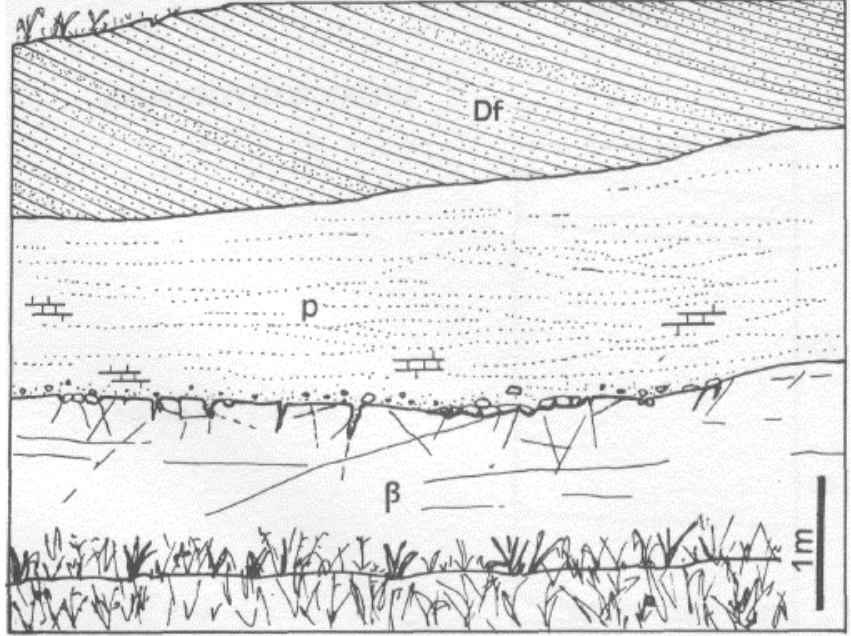

Figura 5 - Brecha basal da Fm. Rio Paraná. Convenções: Jí. basalto (Fm. Serra Geral), p. paleossolo e Df. depósitos de foreset de duna. Ombreira direita da barragem da UHE Porto Primavera (SP)

Figure 5 - Rio Paraná basal breccia. Key: B. basalt (Serra Geral Fm.), p. paleosoil and Df. dune foreset deposits. Site: right shoulder of the Porto Primavera dam (São Paulo State)

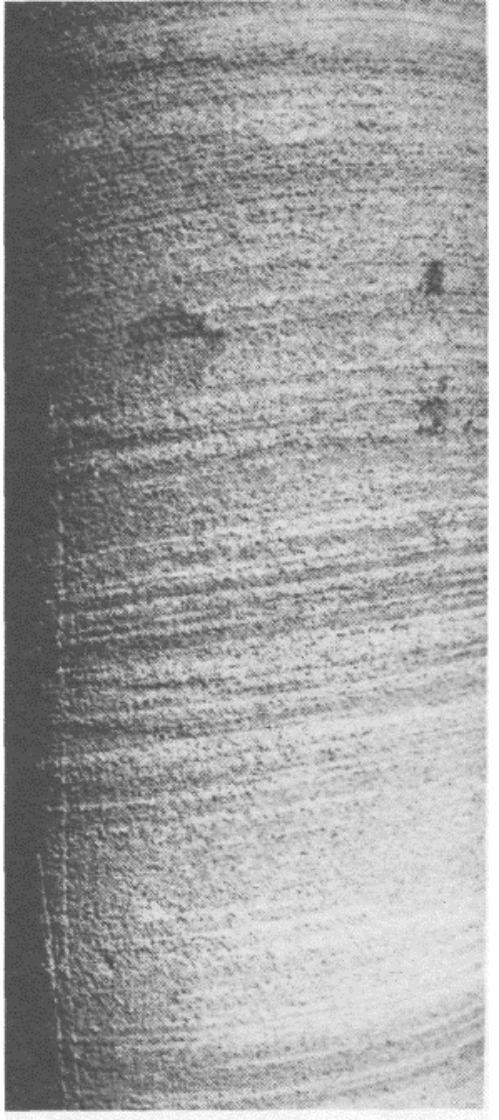

B
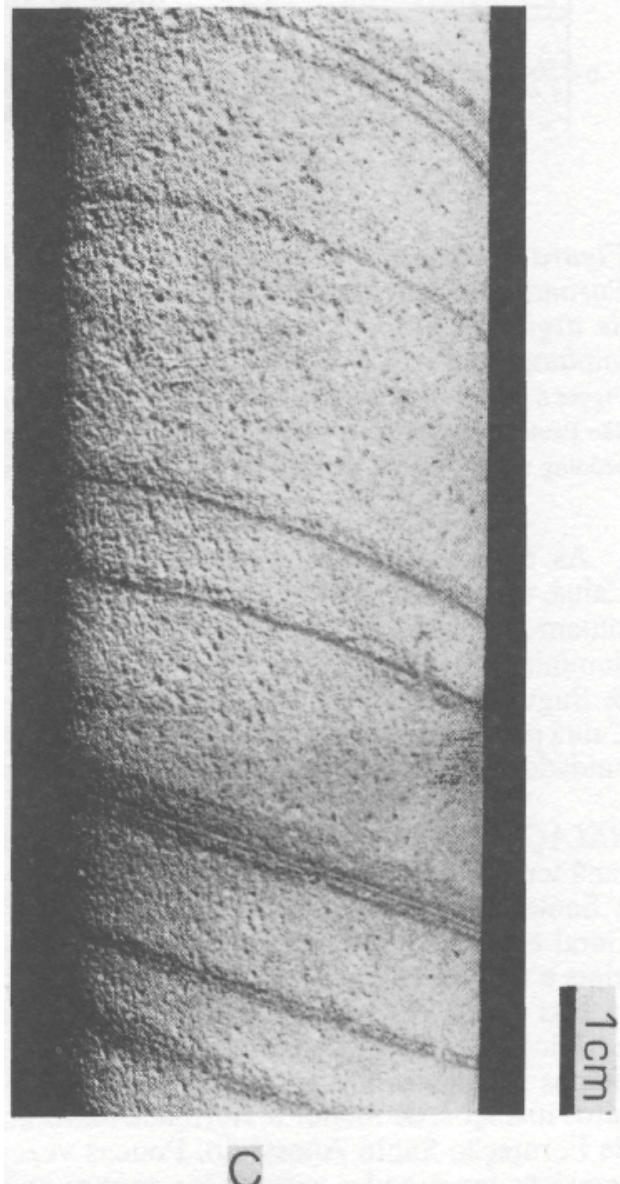

Prancha 2 - Estruturas sedimentares características dos arenitos da Formação Rio Paraná: A. (parte basal da unidade): laminação subhorizontal, maciço na base, com cimentação carbonática e nódulos de esmectita; B. laminacão de baixa inclinação, típica das partes inferiores de foresets de dunas; C. laminação mais inclinada, típica das partes superiores de foresets de dunas. Testemunhos de sondagem na margem esquerda da eclusa da UHE Porto Primavera (SP) Plate 2 - Characteristic sedimentary structures of Rio Paraná Formation: A. (basal part of the unit): subhorizontal laminae, massive at the base, with carbonate cementation and smectite nodules; B. low dipping laminae, typical of lower parts of dune foresets; C. oblique laminae, typical of upper parts of dune foresets. Core drillings from the left margin of the Porto Primavera Hidroelectric Plant canal (São Paulo State) 
Fm. Rio Paraná

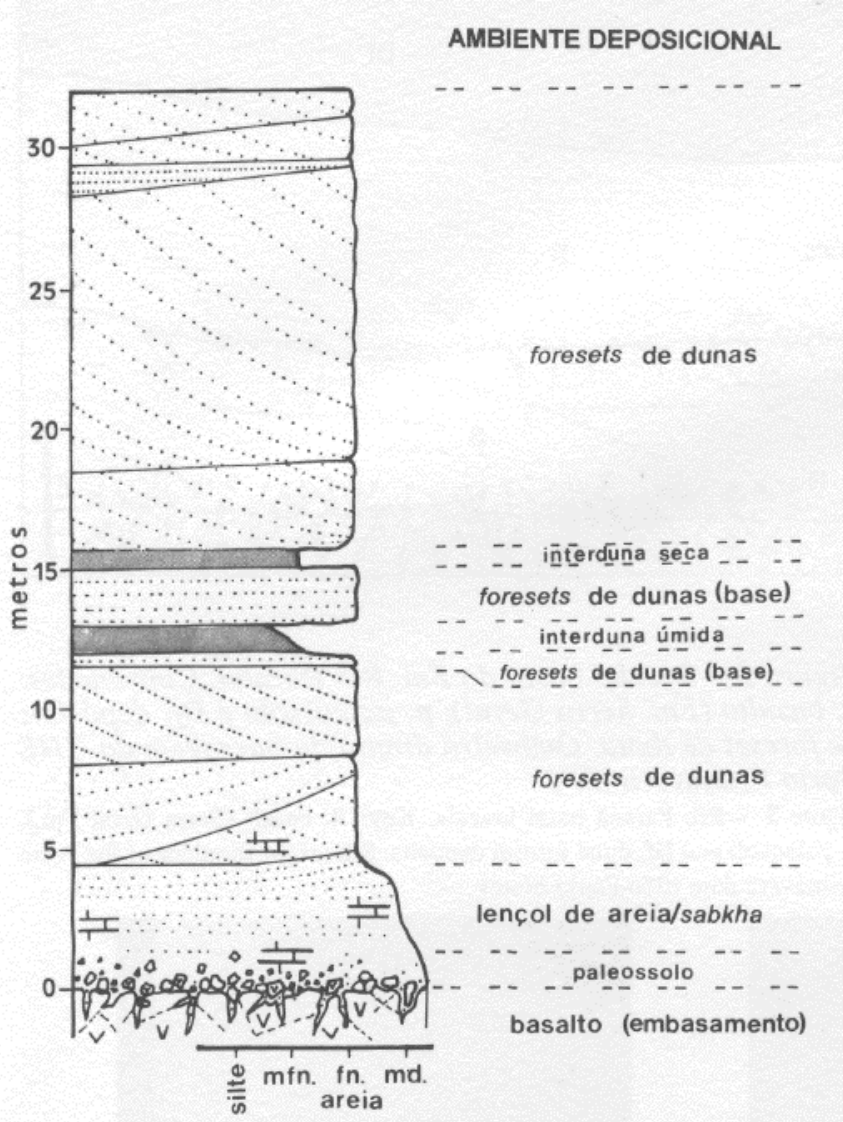

Aspecto geral da unidade

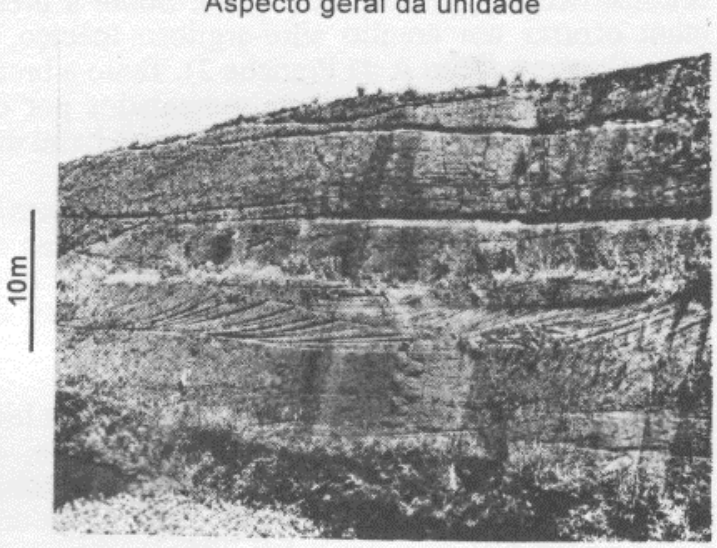

Parede da eclusa da UHE Porto Primavera

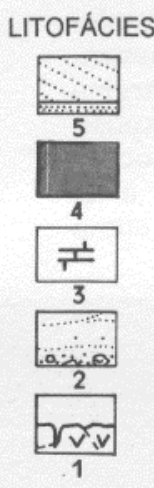

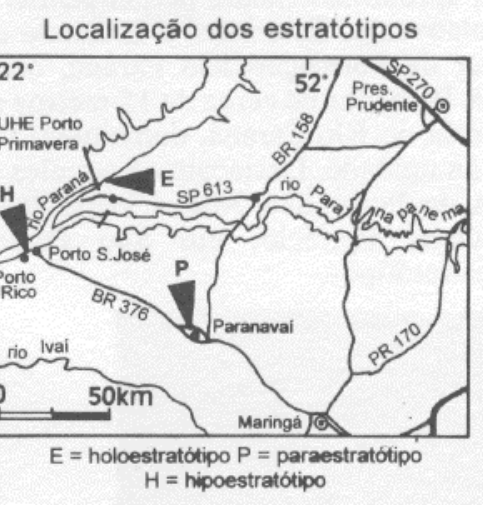

Figura 6 - Seção-tipo (holoestratótipo) da Formação Rio Paraná. Eclusa da usina hidrelétrica Porto Primavera, Pontal do Paranapanema (extremo oeste de São Paulo). Convenções: 1. basalto; 2. arenito maciço com fragmentos de basalto; nódulos de argila e carbonato; 3. cimento carbonático; 4. arenitos maciços a mal estratificados; 5. arenitos com estratificação/ laminação cruzada

Figure 6 - Type-section (holostratotype) of the Rio Paraná Formation. Flood canal of the hydreletric plant, Pontal do Paranapanema region (farwest of the São Paulo State). Key: 1. basalt; 2. massive sandstone with basalt fragments, and clay and carbonate nodules; 3 . carbonate cement; 4. massive to poorly bedding sandstones; 5 . cross-bedding estratification/lamination sandstones

As áreas-tipo anteriormente referidas para "Formação" Caiuá, como as de Washburne (1930) e Soares et al. (1980), situam-se nas barrancas e imediações do Rio Paraná, em domínios da formação ora denominada Rio Paraná. Barcelos \& Suguio (1987) propuseram a seção-tipo da "Formação" Caiuá próximo a Goio Erê (PR), área onde ora se define outra unidade do Grupo Caiuá, conforme se apresenta adiante.

RELAÇÕES ESTRATIGRÁFICAS A Formação Rio Paraná tem contatos transicionais com as formaçôes Goio Erê e Santo Anastácio, basal erosivo com a Formação Serra Geral e erosivo com depósitos cenozóicos arenosos, coluviais e aluviais sobrepostos.

Nas áreas de transição com a Formação Santo Anastácio, as típicas estratificações cruzadas tornam-se paulatinamente menos inclinadas e menos definidas. Passa-se então a arenitos maciços, de menor maturidade textural, característicos da Formação Santo Anastácio. Poucas vezes se observa tal transição em grandes exposições contínuas, como nas cabeceiras da Água Piracaia, oeste de Guaraci (NE de Maringá, PR), no morro da Fazenda Santa Ida (SW de Presidente Prudente, SP), ou nos cortes do Canal de Pereira Barreto (quando em construção).

AMBIENTE DEPOSICIONAL Os arenitos Rio Paraná originaram-se como depósitos da porção central de um sand sea, onde teriam se desenvolvido construções eólicas de grande porte, em complexos de dunas amalgamadas (draas). Verifica-se predomínio dos tipos barcanóides (feições acanaladas em cortes perpendiculares à direção do paleovento, tabulares tangenciais, nos cortes paralelos). As estratificações cruzadas de grande porte ocorrem principalmente na região do Pontal do Paranapanema e extremo noroeste do Paraná, provável área central do paleodeserto Caiuá.

Fácies de interdunas (ou interdraas\} foram identificadas na porção basal da Formação Rio Paraná, em sondagens da região do Pontal do Paranapanema. Trata-se de níveis de arenitos maciços, siltosos no topo (fining upward), com até três metros de espessura, intercalados em arenitos com estratificação cruzada. No corte da eclusa de Porto Primavera verificam-se poucos estratos tabulares maciços (depósitos de interdunas secas, Foto 3 ), em geral associados a superfícies de truncamento de baixa inclinação. (Vide foto da Fig. 6 - seção-tipo).

FÓSSEIS Em arenitos da Formação Rio Paraná foram descritos apenas icnofósseis, marcas de possível Coelossauro (Leonard! 1977, 1989).

Formação Goio Erê ÁREA DE OCORRÊECIA E ESPESSURA A Formação Goio Erê ocorre na parte 
sudeste da área de afloramento dos arenitos Caiuá, no Estado do Paraná, onde apresenta as maiores espessuras, em torno de 50 metros, em superfície.

LITOLOGIA E ESTRUTURAS Esta unidade é constituída por arenitos quartzosos freqüentemente subarcoseanos, marrom-avermelhado a cinza-arroxeado, de granulação fina a muito fina, ocasionalmente média. Dispõem-se em estratos tabulares de poucos metros de espessura com estratificação cruzada, intercalados com bancos de espessura decimétrica a métrica, de aspecto maciço ou com estratificação subhorizontal mal definida. A estratificação cruzada, de médio a pequeno porte (até três metros de altura), é do tipo acanalada ou tabular tangencial na base, respectivamente, em corte perpendicular ou paralelo à direção do paleofluxo. Os arenitos são mineralogicamente matures e texturalmente submaturos. Em 18 amostras analisadas apresentaram quantidades de silte+argila entre 10 e $37 \%$ (média de $25 \%$ ), com teores de argila entre 5 e $15 \%$ (média de $10 \%$ ). Estes resultados são muito semelhantes aos encontrados para as formações Rio Paraná e Santo Anastácio, diferindo apenas quanto ao pequeno incremento na quantidade da fração silte na Formação Goio Erê. Parte da fração argilosa provem de neoformação, não correspondendo à quantidade original de material pelítico depositado como matriz. Em geral os grãos têm superfície fosca encoberta por película de oxido de ferro, com freqüente revestimento de poros por argila autigênica (esmectita), que por alteração intempérica, tende a ser substituída por caulinita.

A laminação por queda de grãos é a feição mais comum nas porções com estratificação cruzada. Nas litofácies correspondentes às partes basais dos foresets de dunas podem ocorrer feições de fluxos de grãos. Nos bancos mais maciços podem ser encontradas laminação e ondulações de adesão, descontínuas e mal definidas; microlaminações cruzadas atribuídas a ondulações eólicas e pequenas dobras convolutas. A Figura 7 apresenta, de modo esquemático, as principais feições e estruturas características da unidade.

$\mathrm{Na}$ parte basal da unidade são comuns intercalações de estratos subhorizontais de espessura decimétrica (até um metro) de arenitos maciços silto-argilosos e brechas, assentados diretamente sobre basaltos da Formação

\section{ESTRUTURAS E FEICÕES CARACTERISTICAS}

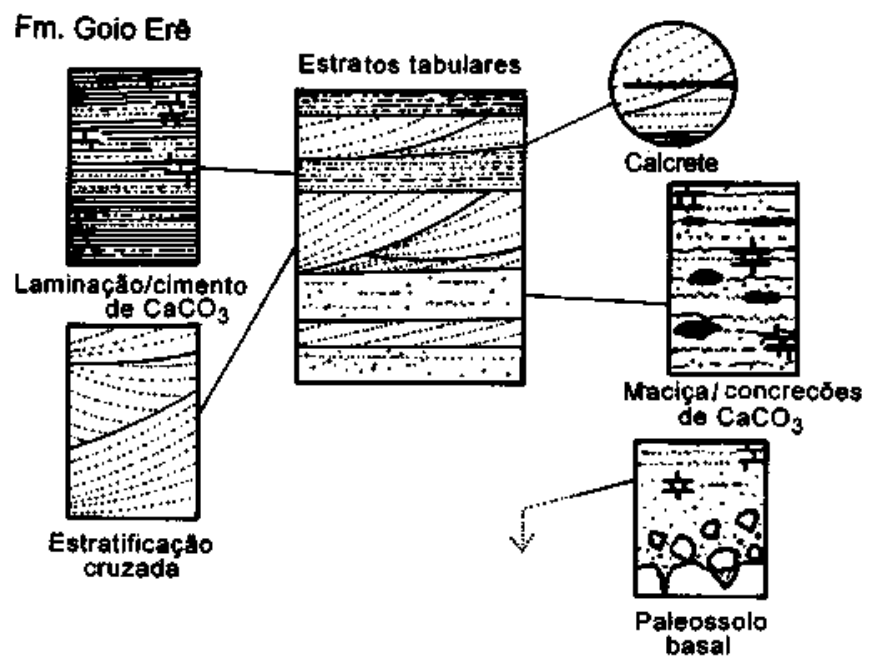

Figura 7 - Feições e estruturas sedimentares características da Formação Goio Erê

Figure 7 - Features and sedimentary structures characteristics of the Goio Erê Formation
Serra Geral, especialmente na região dos vales dos rios Ligeiro, Goio Erê, ribeirões Tamboara e Anhumaí, situada a oeste/noroeste de Campo Mourão, no Paraná (Riccomini et al. 1981). As brechas, sustentadas por matriz arenoargilosa, são compostas por clastos subangulosos centimétricos de basalto e ágata, e de nódulos de argila e calcário.

Nesta unidade a cimentação carbonática é freqüente (Foto 4), localmente formando concrecões com diâmetro centimétrico e crostas duras $(1,5 \mathrm{~cm}$ de espessura, com vários metros de extensão lateral). As crostas ocorrem tanto acompanhando a estratificação cruzada, como em posição subhorizontal (paralela aos diastemas que separam os ban$\cos$ ), às vezes sobrepondo-se discordantemente à estratificação acanalada (Foto 5). Tais feições provavelmente foram criadas sob influência de oscilações do nível freático, que deveria estar próximo da superfície do terreno na época da deposição.

SEÇÃO-TIPO O corte do $\mathrm{km} \mathrm{58,7}$ da rodovia Campo Mourão a Goio Erê (BR 272), situado a poucos quilômetros desta última localidade, é indicado como holoestratótipo da formação (Fig. 8). Como seção complementar (paraestratótipo) da unidade designa-se o corte localizado no km 59,5 da mesma rodovia, onde se observam depósitos de aspecto maciço, com estratificação plano-paralela mal desenvolvida, farto em concrecões carbonáticas. Outras boas exposições da unidade ocorrem à margem da rodovia BR 272, cujo conjunto designa-se como hipoestratótipo da Formação Goio Erê.

RELAÇÕES ESTRATIGRÁFICAS A Formação Goio Erê tem contato transicional com a formação Rio Paraná, contatos erosivos com a Formação Serra Geral (basais) e com depósitos arenosos cenozóicos, aluviais e coluviais (no topo).

AMBIENTE DEPOSICIONAL Esta unidade corresponde a depósitos de áreas periféricas de sand sea, onde não houve condições de acumulação e/ou preservação de grandes construções eólicas. Os estratos arenosos subhorizontais com estratificações cruzadas acanaladas são atribuídos a depósitos de dunas barcanóides de porte moderado a pequeno. As intercalações de estratos arenosos texturalmente imaturos - de aspecto maciço ou pobremente laminados - de brechas basais, formaram-se em áreas de baixo relevo, provavelmente em interdunas úmidas ou aquosas e lagoas efêmeras associadas (sabkhas e playa lakes), encontradas em áreas periféricas do deserto. Neste contexto, desenvolveram-se construções eólicas de menor porte, intimamente associadas com depósitos em estratos subhorizontais, sujeitos a variações do nível freático e a acumulações temporárias de água, provavelmente sob condições evaporíticas.

FÓSSEIS Na área de exposição da Formação Goio Erê foram descritos apenas icnofósseis, marcas provavemente de Therapodas, talvez de Carnossauros e Coelossauros, segundo Leonardi $(1977,1989)$.

Formação Santo Anastácio ÁREA DE OCORRENCIA E ESPESSURA A Formação Santo Anastácio ocorre principalmente nos estados de São Paulo (nas calhas dos afluentes do Rio Paraná) e Mato Grosso do Sul. De modo bem restrito, aflora nos estados do Paraná e Minas Gerais. As espessuras máximas da unidade, verificadas nos vales dos rios Santo Anastácio e Piraporinha (extremo oeste de São Paulo) e Mato Grosso do Sul, oscilam entre 80 e 100 metros. A unidade apresenta espessuras de até 70 metros no Pontal do Paranapanema (Almeida et al. 1981), assim como no Paraná (IPT 1981). 
Fm. Goio Erê

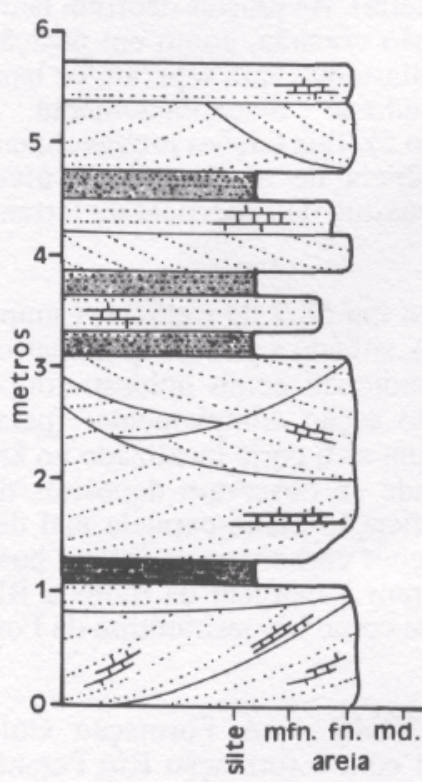

\section{AMBIENTE DEPOSICIONAL}

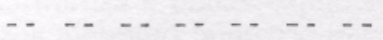

foresets de dunas

intērdūnas úmidas -

base de foresets

foresets de dunas

interdunas úmidas

base de foresets

interdunas ümidās

foresets de dunas

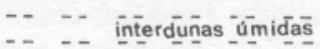

foresets de dunas
Aspecto geral da unidade

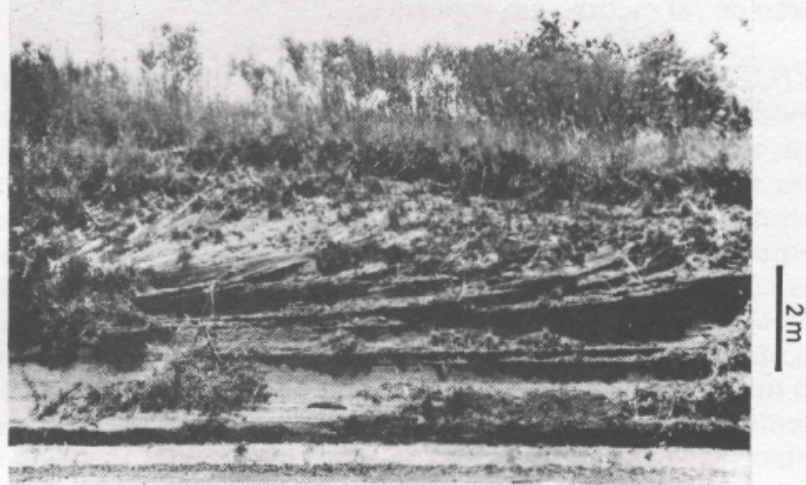

BR 272, km 58,7
Localização dos estratótipos

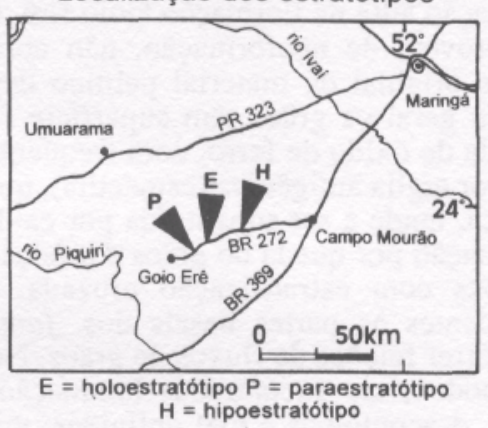

Figura 8 - Seção-üpo (holoestratótipo) da Formação Goio Erê. Km 58,7 da rodovia Campo Mourão-Goio Erê (BR 272), Estado do Paraná. Convenções: L arenito maciço ou com estratificação subhorizontal mal definida, às vezes com cimentação carbonática; 2. arenito com estratificação cruzada; 3. cimento e concreções carbonáticas

Figure 8 - Type-section (holostratotype) of the Goio Erê Formation. 58.7 km of the Campo Mourão-Goio Erê road (BR 272), Paraná State. Key: 1. massive or incipient subhorizontal bedding sandstones, partly with carbonate cement; 2 . cross-bedded sandstone; 3 . carbonate cement and concretions

LITOLOGIA E ESTRUTURAS A Formação Santo Anastácio é constituída por arenitos finos a muito finos, com fração síltica subordinada, essencialmente quartzosos, caracteristicamente maciços. A presença de feldspato em quantia secundária lhes dá, por vezes, caráter subarcoseano. As vezes exibem estratificação plano-paralela ou cruzada de baixa inclinação, mal definidas. Os arenitos são pobremente selecionados, com pequena quantidade de matriz silto-argilosa. A análise granulométrica de nove amostras da unidade, provenientes do extremo oeste de São Paulo e noroeste do Paraná, apontou entre 9 e $30 \%$ de silte+argila (média de 17\%), com 7 a 14\% (média de 9\%) de argila. Os grãos maiores são subangulosos e subarredondados, foscos, encobertos por película de oxido de ferro, responsável pela cor marrom-arroxeado-claro dos arenitos.

Nestas rochas é freqüente a ocorrência de orifícios irregulares de forma tubular, de diâmetro milimétrico e alguns centímetros de comprimento, associados à dissolução de nódulos e concreções carbonáticas (Almeida et al. 1980). Além dos orifícios observam-se, em alguns locais, cimentação carbonática, concreções tubulares e crostas duras de poucos centímetros de espessura. Entretanto, crostas desta natureza podem eventualmente atingir espessuras de até um metro, como no Canal de Pereira Barreto (SP), onde formam calcretes tipo hardpan e honeycomb (Netterberg 1967). No Estado de São Paulo foram descritos, localmente, estratos de lamitos argilosos (e.g. Soares et al. 1980) intercalados em arenitos maciços, por sua vez asZsociados a camadas com estratificação cruzada de pequeno porte. Na Figura 9 estão representadas as feições e estruturas sedimentares encontradas na Formação Santo Anastácio.

A sul do Rio Tietê os arenitos são predominantemente médios a finos, pobres em matriz argilosa e localmente carbonáticos. A norte, onde a unidade se sobrepõe aos basaltos, prevalecem arenitos finos a muito finos, com maior quantidade de matriz argilosa, e maior freqüência de cimentação e nódulos carbonáticos (Almeida et al. 1980).

SECÃO-TIPO Soares et al (1980) alegaram ser impossível definir uma seção-tipo para a formação, devido à inexistência de exposições contínuas e raridade de afloramentos. Afirmaram entretanto que as melhores exposições, ou seja sua área-tipo, estão no vale do Rio Santo Anastácio (extremo oeste de São Paulo). Suguio \& Barcelos (1983) propuseram uma seção-tipo na rodovia BR 158, entre Presidente Venceslau e Marabá Paulista (W de Presidente Prudente, SP), que foi adotada nesta revisão (Fig. 10). Como seção complementar da Formação Santo Anastácio designase aqui os cortes do Canal de Pereira Barreto (SP), onde foram observados, em cortes de alguns quilômetros de extensão, seus contatos com as formações Rio Paraná e Adamantina. No vale do rio Santo Anastácio, a oeste de Presidente Prudente (SP), encontram-se outras boas exposi- 


\section{ESTRUTURAS E FEIÇÕES CARACTERÍSTICAS}

Fm. Santo Anastácio

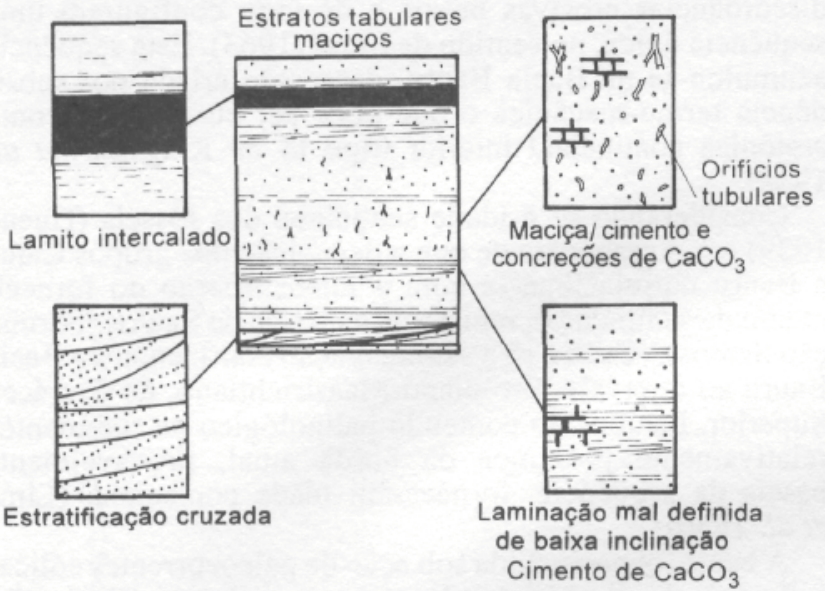

Figura 9 - Feições e estruturas sedimentares características da Formação Santo Anastácio

Figure 9-Features and sedimentary structures characteristics of the Santo Anastácio Formation

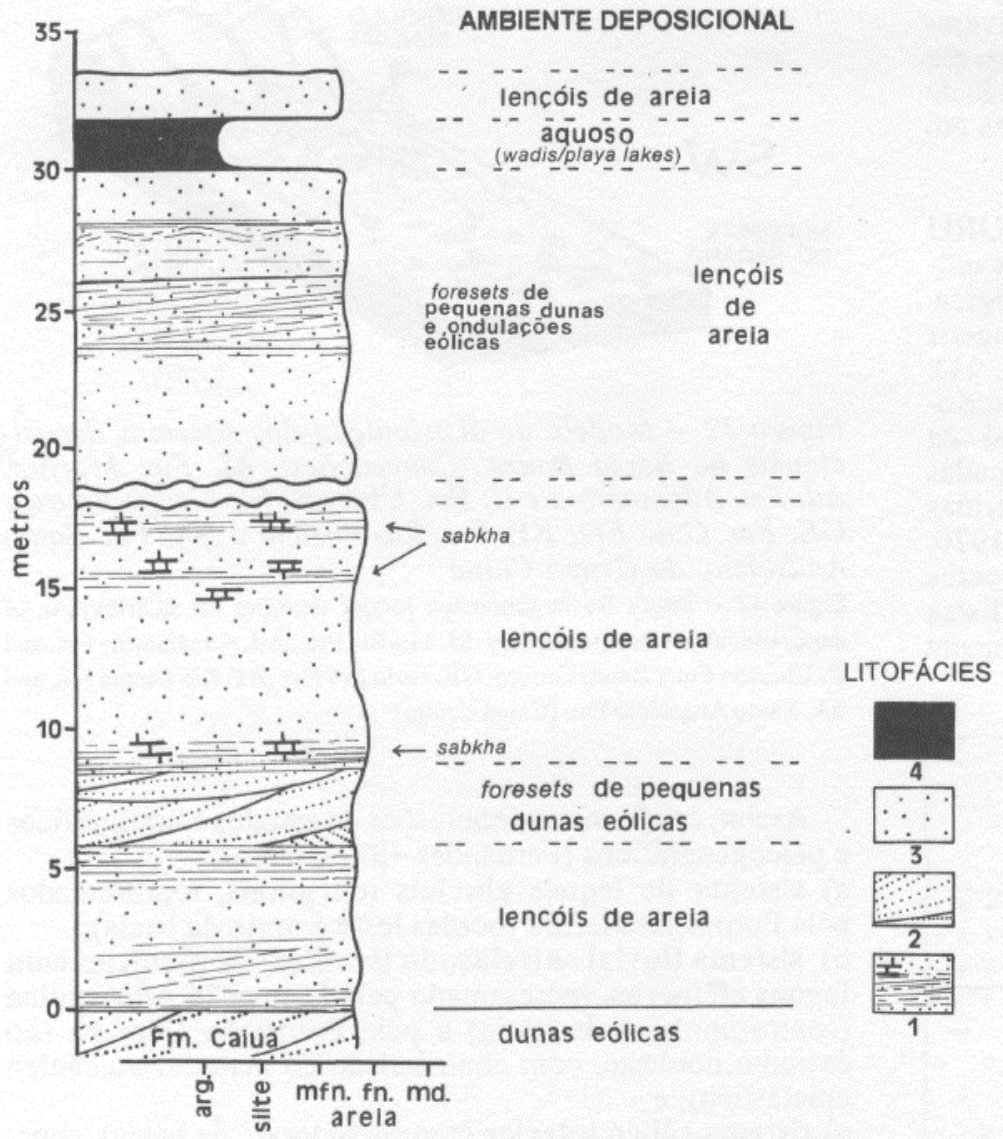

\section{Fm. Santo Anastácio}

ções da unidade, razão pela qual é indicado como seu hipoestratótipo.

ASSOCIACCÃO FACIOLÓGICA MAIRÁ Constitui associação faciológica anômala, de ocorrência restrita à rẹgião a norte da localidade de Mairá (NE de Maringá, PR). É composta por arenitos conglomeráticos texturalmente imaturos, com intercalações lenticulares de arenitos com estratificação cruzada e camadas de conglomerados com espessura decimétrica. Os conglomerados têm matriz arenosa fina a média mal selecionada. Seu arcabouço é formado por clastos arredondados, de dimensões centimétricas (algumas vezes com até $30 \mathrm{~cm}$ de diâmetro maior), às vezes com discreta imbricacão, em estratos grosseiramente definidos. Os clastos são freqüentemente facetados, com forma tetraédrica característica de ventifactos (Fernandes et al 1992), possuindo superfície de brilho peculiar, decorrente da deposição secundária de silica.

RELACÕES ESTRATIGRÁFICAS Em alguns locais onde a Formação Santo Anastácio exibe o contato com basaltos da Formação Serra Geral são descritas delgadas brechas basais, semelhantes às das formações Rio Paraná e Goio Erê. Sousa Júnior (1984) refere-se a situações de con-

Aspecto geral da unidade 
tato erosivo da unidade com a Formação Botucatu. A Formação Santo Anastácio tem contatos transicionais com as formações Rio Paraná e Adamantina (em geral interdigitados), com contatos bruscos locais (diastemas). Tem contato superior erosivo com depósitos cenozóicos arenosos, coluviais e aluviais.

AMBIENTE DEPOSICIONAL A área de exposição da Formação Santo Anastácio contorna a da Formação Rio Paraná, para a qual passa de modo transicional (vertical e lateralmente), adelgaçando-se em direção aos domínios desta unidade. Admite-se, aqui, sua origem como depósitos arenosos extra-dunas (lençóis de areia, wadis, sabkhas), acumulados em extensas planícies desérticas situadas ao redor do sand sea. A Associação Faciológica Mairá foi classificada como depósito de deflação da margem deste campo arenoso, posto que boa parte de seus clastos são ventifactos típicos.

FÓSSEIS A única menção a fósseis na Formação Santo Anastácio refere-se a fragmentos de ossos de possível tetrápode, encontrados no município de Pereira Barreto, SP (Fittipaldi et al 1989).

As estruturas tubulares e orifícios associados à cimentação e concreções carbonáticas - comuns em arenitos da Formação Santo Anastácio, raros nos demais arenitos do Grupo Caiuá - são interpretados como rizólitos. Originaramse, provavelmente, pelo preenchimento de vazios tubulares ou precipitação de carbonato em torno de raízes. Segundo Klappa (1980) e Loope (1988) tais estruturas desenvolvemse em substratos planos, geomorfologicamente estáveis, em sedimentos de alta permeabilidade e com disponibilidade de cálcio, tais como superfícies de deflação com calcretes em clima semi-árido.

A SEQÜÊNCIA IMEOCRETÁCEA E A BACIA BAURU

Diversas são as indicações de contemporaneidade das unidades Bauru e Caiuá que permeam a literatura geológica. Mezzalira \& Arruda (1965) foram os primeiros a sugerir uma possível penecontemporaneidade entre elas (Fig. 11), constatada em mapeamentos geológicos regionais posteriores (e.g. Almeida et al. 1980). Disposição lateral de litofácies e formações, com passagens graduais verificadas em campo e em seções geológicas regionais, são referidas em vários estudos clássicos (Landim \& Soares 1976, Coimbra 1976, Brandt Neto 1977, Stein et al 1979, Soares et al. 1980, Almeida et al. 1980,Petri\&Fúlfaro 1983). Estas indicações foram reunidas e discutidas mais detidamente por Fernandes (1992).

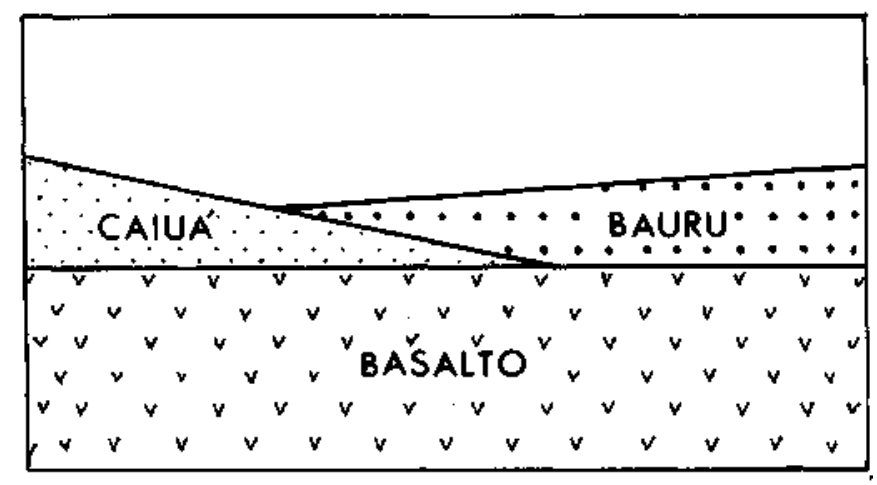

Figura 11 - Desenho esquemático do comportamento das unidades Bauru, Caiuá e Serra Geral, na área do Pontal do Paranapanema (SP), segundo Mezzalira \& Arruda (1965) Figure 11 - Sketch showing the relationships between the Bauru, Caiuá and Serra Geral units in the Pontal do Paranapanema region (São Paulo State), after Mezzalira \& Arruda (1965)
A contemporaneidade parcial das unidades litoestratigráficas dos grupos Caiuá e Bauru e a existência de discordâncias erosivas basais e de topo configuram uma seqüência única, no sentido de Sloss (1963). Esta seqüência acumulou-se na Bacia Bauru, depressão criada por subsidência termo-mecânica e que pode ser classificada como cratônica continental interior (tipo IS de Kingston et al. 1983).

Considerando-se a idade senoniana dos fósseis (Huene 1939) e o pressuposto de que a deposição dos grupos Caiuá e Bauru correlaciona-se com a intensificação do fornecimento de sedimentos, registrada na Bacia de Santos (Formação Santos), associa-se a sedimentação continental na Bacia Bauru ao intervalo Turoniano-Maastrichtiano, do Cretáceo Superior. Estudos do conteúdo palinológico de sedimentos relativamente próximos da borda atual, provavelmente basais da seqüência, forneceram idade coniaciana (Lima et al. 1986).

A bacia foi preenchida sob ação de paleocorrentes eólicas e fluviais de direção dominante para sudoeste (Fernandes 1992), que determinaram a distribuição dos depósitos em três grandes sistemas deposicionais, desenvolvidos em clima quente, semi-árido nas bordas e desértico no interior (Fig. 12).

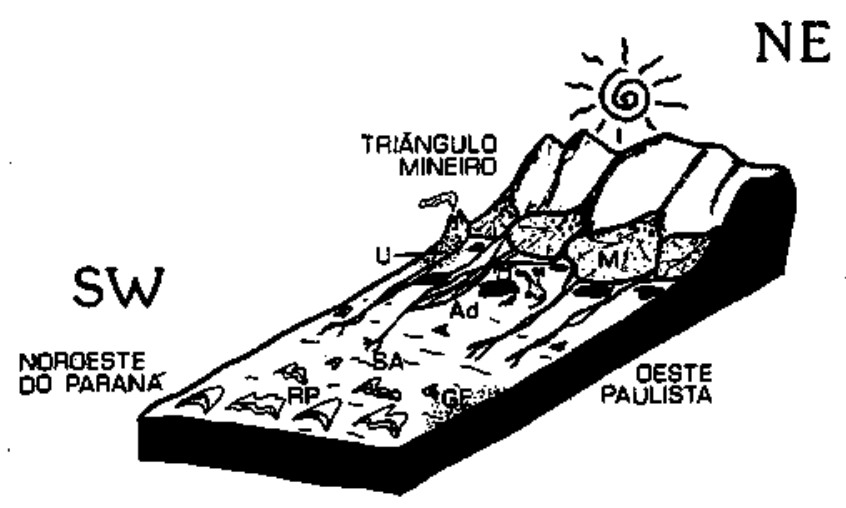

Figura 12 - Modelo de distribuição dos sistemas deposicionais na Bacia Bauru. Convenções: M. Fm. Marília, Ad. Fm. Adamantina e U. Fm. Uberaba (do Grupo Bauru); GE. Fm. Goio Erê, RP. Fm. Rio Paraná e SÁ. Fm. Santo Anastácio, do, Grupo Caiuá

Figure 12 - Bauru Basin schematic model showing the distribution of depositional environments. Key: M. Marília Fm., Ad. Adamantina Fm. and U. Uberaba Fm. (Bauru Group); GE. Goio Erê Fm.,RP. Rio Paraná Fm. and SÁ. Santo Anastácio Fm. (Caiuá Group)

Assim, conforme as conclusões de estudos estratigráficos e paleogeográficos (Fernandes 1992), temos:

a) sistema de leques aluviais marginais, representados pela Formação Marília (bordas leste e norte da bacia); b) sistema fluvial entrelaçado (braided) de planícies com lagoas efêmeras, representado pela Formação Adamantina (centro-nordeste da bacia) e pela Formação Uberaba (no extremo nordeste, com contribuição de material vulcânico epiclástico); e

c)sistema eólico interior (centro-sudoeste da bacia), constituído pela Formação Santo Anastácio (depósitos periféricos em lençóis de areia e planícies extradunas com wadis e sabkhas continentais), Formação Rio Paraná (depósitos do interior do sand sea) e Formação Goio Erê (depósitos eólicos marginais da borda SE).

Os tipos de fósseis conhecidos, bem como sua distribuição, refletem clima inóspito na porção central da bacia (desértico) e mais favorável à vida nas regiões mais próxi- 
mas das bordas norte e nordeste. Tais condições definiram uma faixa em forma de bumerangue, coincidente com a área de exposição das formações Adamantina, Marília (principalmente) e Uberaba. Os registros fossilíferos conhecidos foram separados em três compartimentos paleoecológicos (Coimbra \& Fernandes, 1994), denominados de Peirópolis (setentrional), São José do Rio Preto (central) e Presidente Prudente (meridional).

\section{REFERÊNCIAS BIBLIOGRÁFICAS}

ALMEIDA, F.F.M de. 1956. O planalto basáltico da Bacia do Paraná. Bol. Paul. Geogr., 24:3-34.

ALMEIDA, F.F.M. de \& BARBOSA, O. 1953. Geologia das quadrículas Piracicaba e Rio Claro, Estado de São Paulo. Bol. DGM/DNPM, 143:1-96.

ALMEIDA, M.A de; STEIN, D.P ; MELO, M.S de; BISTRICHI, C.A.; PONCANO, W.L.; HASUI, Y. \& ALMEIDA, F.F.M. de. 1980. Geologia do Oeste Paulista e áreas fronteiriças dos estados de Mato Grosso do Sul e Paraná. In: CONG. BRAS. GEOL., 31. Camboriú, 1980. Anais... Camboriú, SBG. v.5, p. 2799-2812.

ALMEIDA, M.A. de;DANTAS, A.S.L.; FERNANDES, L.A.; SAKATE, M.T.; GIMENEZ, A.F.; TEIXEIRA, A.L.; BISTRICHI, C.A. \& ALMEIDA, F.F.M. de. 1981. Considerações sobre a estratigrafia do Grupo Bauru na região do Pontal do Paranapanema no Estado de São Paulo. In: SIMP. REG. GEOL., 3., Curitiba, 1981. Atas... São Paulo, SBG.v.2,p.77-89.

ARID, F.M. 1970. A Formação Bauru na região norte-ocidental do Estado de São Paulo. In: CONG. BRAS. GEOL., 24. Brasília, 1970. Rés. Conf. Com... Brasilia, SBG. p. 373-377.

BAKER, C.L. 1923. The lava field of the Paraná Basin, South America. $J$ Geol, 31(1):69-79.

BARCELOS, J.H. 1984. Reconstrução paleogeográfica da sedimentação do Grupo Bauru baseada na sua redefinição estratigráfica parcial em território paulista e no estudo preliminar fora do Estado de São Paulo. Rio Claro. (Tese de Livre-Docência, IGCE/UNESP). 190p.

BARCELOS, J.H. \& SUGUIO, K. 1987. Correlação e extensão das unidades litoestratigráficas do Grupo Bauru definida em território paulista, nos estados de Minas Gerais, Goiás, Mato Grosso do Sul e Paraná. In: SIMP. REG. GEOL., 6. Rio Claro, 1987. Atas... Rio Claro, SBG/ Núcleo SP. v.1, p. 313-321.

BIGARELLA, J.J. 1949. Contribuição à petrografia dos arenitos da Série São Bento. Arq. Biol Tecn., 4:141-216.

BIGARELLA, J.J. \& MAZUCHOWSKI, J.Z. 1985. Visão integrada da problemática da erosão. SIMP. NAC. CONTR. EROSÃO, 3. Maringá, 1985. Livro guia... Curitiba, ABGE/ADEA. 232p.

BRANDT NETO, M. 1977. Estratigrafia da Formação Bauru na região do baixo Tietê. São Paulo. 74p. (Dissertação de Mestrado, IGc/USP).

BRANDT NETO, M. 1984. O Grupo Bauru na região centro-norte do Estado de São Paulo. São Paulo. 2v. (Tese de Doutoramento, IGc/USP).

COIMBRA, A.M. 1976. Arenitos da Formação Bauru: estudo de áreas fonte. São Paulo. 2v. (Dissertação de Mestrado, IGc/USP).

COIMBRA, A.M. \& FERNANDES, L.A. A paleogeografia da Bacia Bauru (Cretáceo Superior, Brasil). In: CONGR. ARC. PALEONT BIOESTR., 6. Trelew, 1994. Actas... Trelew, 85-90.

COIMBRA, A.M.; FERNANDES, L.A. \& HACHIRO, J. 1992. Sismitos do Grupo Caiuá (Bacia Bauru, Ks) no Pontal do Paranapanema (SP). In: CONG. BRAS. GEOL., 37. São Paulo, 1992. Boi. Rés. Exp... São Paulo, SBG. v. 2:503-504.

COIMBRA, A.M.; COUTINHÇ, J.M.V.; BRANDT NETO, M. \& ROCHA G.A. 1981. Lavas fonolíticas associadas ao Grupo Bauru no Estado de São Paulo. In: SIMP. REG. GEOL., 3. Curitiba, 1981. Atas... Curitiba, SBG/Núcleo SP. v. 1,p. 324-327.

COUTINHO, J.M.V.; COIMBRA, A.M.; BRANDT NETO, M. \& ROCHA G. A. 1982. Lavas alcalinas analcimíticas associadas ao Grupo Bauru (Kb) no Estado de São Paulo, Brasil. In: CONGR. LATINAM. GEOL., 5. Buenos Aires, 1982. Actas... Buenos Aires, Serv. Geol. Nac. v. 2, p. 185-195.

FERNANDES, L.A. 1992.A cobertura cretácea suprabasáltica no Paraná e Pontal do Paranapanema (SP): os grupos Bauru e Caiuá. São Paulo. 129p. (Dissertação de Mestrado, IGc/USP).

FERNANDES, L.A.; COIMBRA, A.M. \& HACHIRO, J. 1992. Ventifactos da Litofácies Mairá, Formacão Santo Anastácio (Grupo Bauru, Ks) In: CONG. BRAS. GEOL., 37. São Paulo, 1992. Boi Rés. Exp... São Paulo, SBG. v. 2:504-506

FERNANDES, L.A.; COIMBRA, A.M. \& BRANDT NETO, M. 1993. Silicificação hidrotermal neocretácea na porção meridional da Bacia Bauru. Rev. Inst. Geol, 14(2): 19-26.

FERNANDES, L.A.; COIMBRA, A.M.; BRANDT NETO, M. \& DESENZI A.L.G. Argilominerais e evolução diagenética do Grupo Caiuá. Rev. Bras. Geoc., 24(2):90-96.

FITTIPALDI, F.C.; FERNANDES, L.A.; SIMÕES, M.G. \& COIMBRA A.M. 1989. Primeira ocorrência de tetrápodes na Formacão Santo Anastácio (Cretáceo da Bacia do Paraná). In: CONGR. BRAS. ZOOL.,
16. João Pessoa, 1989. Resumos... João Pessoa. SBZ p. 89-90.

FLORENCE, G. \& PACHECO, J. 1929. Carta Geológica do Estado de São Paulo, Brasil São Paulo, Com. Geogr. Geol. Escala 1:2.000.000.

FULFARO, V. J. \& BARCELOS, J.H. 1992. A tectônica pós-deposicional e a reconstituicão paleogeográfica: o exemplo no Grupo Bauru. In: SIMP. BACIAS CRETAC. BRÁS., 2. Rio Claro, 1992. Rés. Exp... Universidade Estadual Paulista, p. 132-3.

FÚLFARO, V.J. \& BARCELOS, J.H. 1993. Fase rifte na Bacia Sedimentar do Paraná: a Formacão Caiuá. Geociências, 12(1):33-45.

GONZAGA DE CAMPOS, L.F. 1905. Reconhecimento da zona compreendida entre Bauru e Itapura. São Paulo, E. F. Noroeste do Brasil. Tipografia Ideal. 40p.

HASUI, Y. 1968. A Formação Uberaba. In: CONG. BRAS. GEOL., 22 Belo Horizonte, 196\%. Anais... Belo Horizonte, SBG. p. 167-179.

HUENE, F.VON. 1939. Carta de F.von Huene ao Dr.Euzébio de Oliveira. Min. Metal., Rio de Janeiro, 4(22): 190.

INSTITUTO GEOLÓGICO E GEOGRÁFICO. 1974. Mapa geológico do Estado de São Paulo. São Paulo, IGG. Escala 1:1.000.000.

INSTITUTO DE PESQUISAS TECNOLÓGICAS DO ESTADO DE SÃO PAULO S/A. 1981. Mapeamento geológico do bloco SF-22-T (ACS73). São Paulo. Relatório IPT, 14.845. v. 1. (inédito).

KLAPPA, C.F. 1980. Rhizoliths in terrestrial carbonates: classification, recognition, genesis and significance. Sedimentology, 27(6):613-629.

KINGSTON, D.R.; DISHROON, C.P.; WILLIAMS, P.A. 1983. Global basin classification system. AAPG Bull, 67(12):2175-2193.

LANDIM, P.M.B. \& SOARES, P.C. 1976. Estratigrafia da Formação Caiuá. In: CONG. BRAS. GEOL., 29. Ouro Preto, 1976. Anais.. Ouro Preto, SBG. v.2, p. 195-206.

LEONARDI, G 1977. Two new ichnofaunas, vertebrates and invertebrates, in the eolian cretaceous sandstones of the Caiuá formation in northwest Paraná. In: SIMP. GEOL. REG., 1. São Paulo, 1911.Atas... SãoPaulo.SBG/NúcleoSP.p. 112-128.

LEONARDI, G. 1989. Inventory and statistics of the South American dinossaurian ichnofauna and its paleobiological interpretation. In: Gillete, D.D. \& Lockley, M.G. (eds). Dinosaur tracks and traces. Cambridge, Cambridge University, p. 165-178.

LIMA, M.R. de; MEZZALIRA, S.; DINO, R. \& SAAD, A.R. 1986. Descoberta de microflora em sedimentos do Grupo Bauru, Cretáceo do Estado de São Paulo. Rev. Inst. Geol., 7(1/2):5-9.

LOOPE, D.B. 1988. Rhizoliths in ancient eolianites. Sedim. Geol, 56:301-314.

MAACK, R. 1941. Algumas observações a respeito da existência e da extensão do arenito superior São Bento ou Caiuá no Estado do Paraná. Arc. Mus. Par., 2:107-129.

MEZZALIRA, S. 1982. Aspectos bioestratigráficos e hidrogeológicos do Grupo Bauru. In: ENC. GEOL. HIDROGEOL.: GR. BAURU EST. S. PAULO, 1. São Paulo, 1981. SBG/Núcleo SP-ABAS. p. 20-35. (Publ. Esp.)

MEZZALIRA, S. \& ARRUDA, M.R. 1965. Observações geológicas na região do Pontal do Paranapanema, Estado de São Paulo. An. Acad. Brás. Cl, 37(1):69-77.

NETTERBERG, F. 1967. Some roadmaking properties of South African Calcretes. In:. REG. CONF. AFRICA SOIL MECH. \& FOUND. ENG., 4. Proceedings... Capetown, p. 77-81.

PACHECO, J.A.A. 1913. Notas sobre a geologia do vale do Rio Grande a partir da foz do Rio Pardo até sua confluência com o Rio Paranaíba. In: Exploração do Rio Grande e seus afluentes. São Paulo, Comm. Geogr. Geol. p. 33-38.

PETRI, S. \& FÚlFARO, J.V. 1983. Geologia do Brasil. São Paulo, T.A. Queiroz/EDUSP. 634p.

RICCOMINI, C; GIMENEZ FILHO, A; PIRES NETO, A.G.; STEIN, D.P.; ALMEIDA, F.F.M. de; DEHIRA, L.K.; MELO, M.S. de; BRAGA, T. de O. \& PONÇANO, W.L. 1981. Características da porção basal da Formação Caiuá no noroeste do Paraná. In: SIMP. REG GEOL., 3. Curitiba, 1981. Atas... Curitiba, SBG/Núcleo SP. v. 2, p. 34-46.

SAAD, A.R.; CAMPANHA, V.A.; CABRAL JR., M.: ETCHEBEHERE M.L.C.; PULEGHINI FOLHO, P.; MOTTA, J.F.M. \& SILVA, F. de P E. 1988. Cenários do Grupo Bauru (K) no Estado de São Paulo. In: CONG. BRAS. GEOL., 35. Belém, 1988. Anais... Belém, SBG. v. 2., p. 894-904.

SETZER J. 1943. Os solos da noroeste. São Paulo. Secr. Agr. Ind. Com. Est. S.Paulo. 15p.il. 
SLOSS, L.L. 1963. Sequences in the cratonic interior of North America. Geol Soc. Am. Bull., 74(2):93-114.

SOARES, P.C.; LANDIM, P.M.B.; FÚLFARO, V.J. \& SOBREIRO NETO, A.F. 1979. Ensaio de caracterização estratigráfica do Cretáceo no Estado de São Paulo. In: SIMP. REG. GEOL., 2. Rio Claro, 1979. Boi. Rés... Rio Claro, SBG/Núcleo SP. p. 30-31.

SOARES, P.C.; LANDIM, P.M.B; FÚLFARO, VJ \& SOBREIRO NETO, A.F. 1980. Ensaio de caracterização do Cretáceo no Estado de São Paulo: Grupo Bauru. Rev. Bras. Geoc., 10(3): 177-185.

SOUSA JUNIOR., J.J. de. 1984. O Grupo Bauru na porção setentrional da Bacia Sedimentar do Paraná. In: CONG. BRAS. GEOL., 33. Rio de Janeiro, 1984. Anais... Rio de Janeiro, SBG. v.2, p. 944-957.

STEIN, D.P.; MELO, M.S. de; BISTRICHI, C.A.; ALMEIDA, M.A. de HASUI, Y.; PONÇANO, W. \& ALMEIDA, F.F.M. de. 1979. Geologia de parte dos vales dos rios Paraná e Paranapanema. In: SIMP. REG. GEOL., 2. Rio Claro, 1979. Atas... Rio Claro, SBG/Núcleo SP. v. 2 p. 291-306.
SUGUIO, K. 1981. Fatores paleoambientais e paleoclimáticos e subdivisão estratigráfica do Grupo Bauru. In: FM. BAURU EST. S. PAULO REG. ADJ. São Paulo, 1980. Colei. Trab. Deb... São Paulo, SBG/ Núcleo SP. p. 15-26.

SUGUIO, K. \& BARCELOS, J.H. 1983. Significado paleoambiental de estrutura "boudinóide" e outras feições presentes na seção tipo da Formação Santo Anastácio do Grupo Bauru, Estado de São Paulo. Boi. IG-USP, 14:49-54.

WASHBURNE, C.W. 1930. Petroleum geology of the state of São Paulo. Brasil. Boi. Comm. Geogr. Geol., 22:1-282.

MANUSCRITO A 816 Recebido em 16 de junho de 1994 Revisão do autor em 1 de março de 1996 Revisão aceita em 1 de abril de 1996 